\title{
Técnicos del IAPH intervienen nueve libros con obra gráfica original de Picasso
}

El Taller de Patrimonio Documental y Gráfico del Instituto Andaluz del Patrimonio Histórico ha intervenido nueve libros con obra gráfica original de Picasso, pertenecientes al Fondo Bibliográfico del Museo Picasso de Málaga. La recuperación de las encuadernaciones y de los estuches originales ha centrado los trabajos de restauración y conservación ceñidos, en términos generales, al criterio de mínima intervención.

( Arriba, Dessins d’un demi-sièle tras la intervención. Debajo, proceso de intervención de la tapa de Cahiers d’arts / Fotos: EuGENIO FERNÁNDEZ RUIZ, IAPH

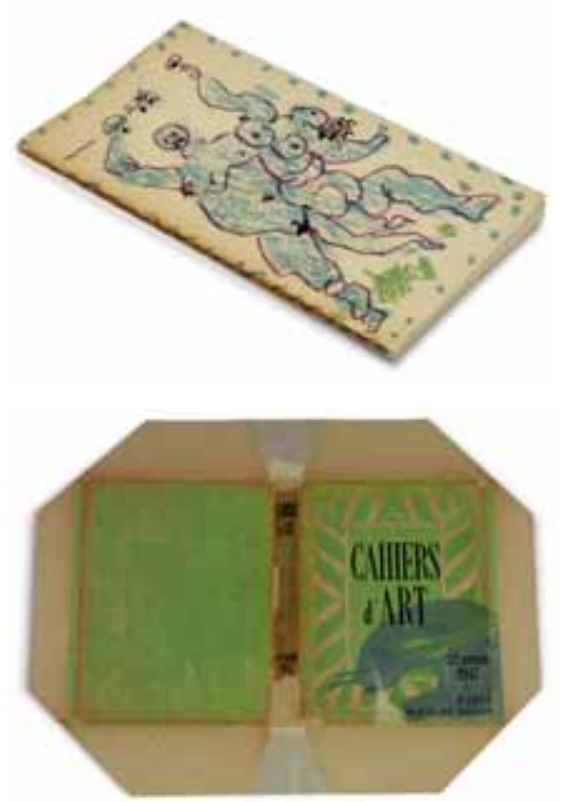

Los nueve libros, en general, mantenían un buen estado de conservación aunque se detectaron alteraciones que afectaban sobre todo a las encuadernaciones. Provocadas por agentes de degradación externos, dichas alteraciones se debían al uso y manipulación inadecuados, y se localizaban en la propia estructura de las encuadernaciones o en sus sistemas de protección originales. Tras el análisis de patologías y principales causas de alteración, se optó por proponer, en términos generales, una intervención de conservación muy ceñida al criterio de mínima intervención, que fortaleciera los puntos débiles de las encuadernaciones. La intervención se ha basado en la recuperación de las encuadernaciones y de los estuches originales. La mayoría de las encuadernaciones presentaba un deterioro propio del uso, es decir, desgastes y roturas en las cubiertas; suciedad y deformaciones en los cortes y esquinas; y desprendimientos de cuadernillos y hojas. En el caso de uno de los dos estuches de protección originales -Shakespeare de L. Aragón (Cercle D’Art, Paris, 1965)- hubo que desmontar toda la cubierta para sustituir la estructura de cartón interna, alisar y tratar la tela de seda y volver a montar todo el conjunto. En cuanto al otro estuche - A los toros avec Picasso de André Sauret (Editions du Livre, Montecarlo, 1961)-, dado su buen estado de conservación, la intervención se centró en pequeños desperfectos puntuales, sin necesidad de desmontar la obra.
Cahiers d’Art (catálogo, 1947) ha requerido el mayor número de actuaciones, debido al peso y grosor del bloque, en gran parte descosido, y al avanzado deterioro de las cubiertas. Se procedió a la restauración de la costura y consolidación del lomo, y a la laminación completa y reintegración de lagunas en las cubiertas.

A las tres obras referidas, se les confeccionó un estuche de protección a medida. El resto de las obras-Dessins d'un demi-siècle de Maurice Jardot (Berggruen, París, 1956); Picasso, 60 ans de gravures: I. Eaux-fortes, pointes sèches, aquatintes II. Lithographies III. Gravures sur bois et linoléum Affiches (Berggruen, París, 1964); Le ballet, Arts du Monde de Boris Kochno (Hachette, París, 1954); Picasso: Cent cinquante céramiques originales (Maison de la Pensée Francaise, París, 1958); y los dos ejemplares de Picasso: 30 cuadros inéditos, 1917-1960 (Sala Gaspar, Barcelona, 1960)- se ha sometido, al desmontaje y limpieza de cubiertas y cuerpo del libro; restauración de costuras y refuerzo de lomos; reparación de las cubiertas; embutido de bloques y cubiertas, y acabados finales.

Con un presupuesto de 7380 euros, las actuaciones y las condiciones de almacenamiento y depósito del Museo Picasso de Málaga, que los técnicos del IAPH consideran óptimas, permitirán la futura conservación de esta obra.

\section{Andrés Alés Sancristóbal}

Centro de Intervención, IAPH 